\title{
NOVIDADES NO FRONT: EXPERIÊNCIAS COM HUMANIDADES DIGITAIS EM UM CURSO DE HISTÓRIA NA PERIFERIA DA GRANDE SÃO PAULO
}

News on the front: experiences with digital humanities in a History course in the suburbs of the great São Paulo area.

Noticias en el front: experiencias con humanidades digitales en un curso de historia en las afueras de la gran São Paulo

\author{
LUIS ANTONIO COELHO FERLA ${ }^{I^{*}}$ \\ LUÍS FILIPE SILVÉRIO LIMA ${ }^{\mathrm{I}^{* *}}$ \\ BRUNO FEITLER ${ }^{1 * * *}$
}

DOI: http://dx.doi.org/10.1590/S2178-14942020000100007

\section{RESUMO}

A partir das indefinições do que sejam as humanidades digitais e da concepção de que o compartilhamento de expe-

\footnotetext{
'Universidade Federal de São Paulo (Unifesp), São Paulo (SP),Brasil'

* Professor Associado do Departamento de História e Coordenador do lab.hum - Laboratório de Humanidades Digitais da Universidade Federal de São Paulo (Unifesp) (ferla@unifesp.br). ORCID ID: http://orcid.org/0000-0003-3617-2560.

** Professor Associado do Departamento de História. Universidade Federal de São Paulo (Unifesp), (Ifslima@unifesp.br). ORCID ID: http://orcid.org/0000-0002-5924-5382.
}

*** Professor Associado do Departamento de História. Universidade Federal de São Paulo (Unifesp), (feitler@unifesp.br). ORCID ID: http://orcid.org/0000-0003-1468-5680.

Artigo recebido em $1^{\circ}$ de agosto de 2019 e aprovado para publicação em 3 de dezembro de 2019. 
riências concretas pode enriquecer essa discussão, são apresentadas iniciativas levadas a cabo no Departamento de História da Universidade Federal de São Paulo (Unifesp). Para dar maior diversidade ao material apresentado, foram escolhidos projetos de um grupo de pesquisas e de uma disciplina de graduação. Assim, com centros de gravidade na pesquisa e na docência, os projetos analisados propõem um maior reconhecimento do papel do graduando nas humanidades digitais. Da análise sai reforçado o paradoxo de que os trabalhos em humanidades digitais são institucionalmente subvalorizados, ao mesmo tempo que facilitam a colaboração e a livre circulação do conhecimento.

PALAVRAS-CHAVE: SIG histórico; Plataformas digitais; Ciência aberta; História de São Paulo; Wikipédia; História moderna.

\begin{abstract}
Drawing on the vagueness of what digital humanities are, and the view that sharing concrete experiences enriches that debate, the article offers an account of initiatives undertaken within the History Department of the Federal University of São Paulo (Unifesp). To give greater diversity to the material presented, projects were chosen from a research group and an undergraduate course. With centers of gravity in research and teaching, the projects analyzed propose greater recognition of the student's role in digital humanities. The analysis also reinforces the paradox that digital humanities projects are institutionally undervalued, while facilitating the collaboration and the free circulation of knowledge.
\end{abstract}

KEYWORDS: Historical GIS; Digital platforms; Open science; History of São Paulo; Wikipedia; Modern history.

\title{
RESUMEN
}

Basándose en la vaguedad de las humanidades digitales y la visión de que compartir experiencias concretas puede enriquecer esa discusión, el artículo ofrece una reseña de las iniciativas emprendidas en el Departamento de Historia de la Universidad Federal de São Paulo (Unifesp). Para dar mayor diversidad al material presentado, se seleccionaron proyectos de un grupo de investigación y una disciplina de pregrado. Con los centros de gravedad en la investigación y la enseñanza, los proyectos analizados proponen un mayor reconocimiento del papel del estudiante en las humanidades digitales. El análisis refuerza la paradoja de que el trabajo en las humanidades digitales está subvaluado institucionalmente, al tiempo que facilita la colaboración y la libre circulación de conocimiento.

PALABRAS ClAVE: GIS histórico; Plataformas digitales; Ciencia abierta; Historia de São Paulo; Wikipedia; Historia moderna. 


\section{QUAIS HUMANIDADES DIGITAIS?}

$\mathrm{M}$ uitas foram e têm sido as tentativas de definir o que sejam as humanidades digitais. Em 2004, a publicação Companion to digital humanities propôs, desde o título, um novo conceito para dar conta das articulações entre humanidades e tecnologias digitais e substituir, assim, o mais antigo e supostamente mais restritivo expresso por "computing humanities" (Schreibman et al., 2004). Em 2016, surge A new companion to digital humanities (Schreibman et al., 2016), em uma tentativa de atualizar as discussões apresentadas em 2004. Entre uma coisa e outra, teve grande impacto a obra Debates in digital humanities (Gold, 2012), também atualizada por uma nova edição em 2016 (Gold e Klein, 2016). Faz todo sentido que coletâneas que discutam temas associados à tecnologia digital sejam pressionadas a serem periodicamente reapresentadas ao público, buscando maior conformidade com os novos contextos sociotécnicos, que se sucedem em velocidade desconcertante. Por outro lado, coletâneas referenciais como essas, editadas e atualizadas após um tempo, constituem um corpus privilegiado para analisar como uma comunidade constrói a imagem — ou várias imagens — de si mesma, que expectativas de futuro são propostas e que transformações dessas perspectivas são reconhecidas.

Nesse exercício analítico, duas conclusões impõem-se ao leitor: o fortíssimo centro de gravidade no mundo anglo-saxão das humanidades digitais e a persistência da falta de uma identidade consensual ao "campo". A primeira questão já foi reconhecida por várias das reflexões do corpus proposto, e iniciativas importantes vêm sendo tomadas para aumentar a diversidade do ecossistema das humanidades digitais. ${ }^{1}$ A segunda representa uma permanência cada vez mais perturbadora, haja vista a expectativa de que o acúmulo de experiências e de reflexões ao longo de cerca de duas décadas tivesse como legado, ao menos, uma definição mais precisa do que seriam as humanidades digitais. Não foi o que se deu, e muitas das perguntas e tentativas de respostas a essa questão, apresentadas na "obra inaugural" de 2004, subsistem até o presente. Mais do que isso, parecem ter se tornado mais frequentes e problemáticas com o tempo.

Susan Schreibman, Ray Siemens e John Unsworth, no texto introdutório da coletânea de 2004, assumiam de saída uma visão disciplinar das humanidades digitais:

Esta coleção é um ponto de inflexão no campo das humanidades digitais: pela primeira vez uma ampla gama de teóricos e de profissionais, tanto aqueles no campo há décadas quanto os mais recentemente incorporados, especialistas da área, cientistas da computação e especialistas em biblioteconomia e ciência da informação, uniram-se para pensar as humanidades digitais como uma disciplina por si só, e para refletir sobre como ela se relaciona com áreas de humanidades acadêmicas tradicionais. (Schreibman et al., 2004: xxiii)² 
Como se vê, não apenas os autores deixam claro sua posição, como sugerem certa aceitação geral dela. Essa perspectiva acaba dando o tom da obra, dedicada predominantemente a apresentar as crescentes relações cotidianas e empíricas entre o mundo das humanidades e as tecnologias digitais, sem muita preocupação em propor identidades e epistemologias. Mas, na atualização do compêndio, publicada mais de uma década depois, os mesmos autores iniciam a obra justamente relativizando e problematizando a afirmação que fizeram em 2004: "Ainda é discutível se as humanidades digitais devem ser vistas como uma 'disciplina por si só', e não como um conjunto de métodos afins, mas não se pode duvidar, em 2015, que se trata de um campo de atuação vibrante e em rápido crescimento" (Schreibman et al., 2016: xvii). 0 recuo entre uma concepção pretensamente unânime de afirmação disciplinar para um " campo de atuação vibrante e em rápido crescimento" é patente. Ao longo da obra, nos textos dos autores convidados, a questão reaparece diversas vezes, seja na forma explícita de propostas para resolvê-la, seja em variações mais implícitas que a consideram já resolvida, de uma forma ou de outra, mas sempre ajudando a compor um quadro geral de dissonância e indefinição.

Por exemplo, Jennifer Edmond (2016: 256) considera que "as humanidades digitais como um campo é essencialmente interdisciplinar e frequentemente intersetorial [...]". Já Willard McCarty (2016: 79) afirma que as "[...] humanidades digitais estão particularmente em perigo por carecerem de um forte senso de si". Laura Hughes, Panos Constantopoulos e Costis Dallas (2016: 151), por sua vez, contrapõem a grande difusão das humanidades digitais com sua falta de identidade, sugerindo uma tensão crescente entre uma coisa e outra: "Essa proliferação de conteúdo digital, sua disseminação, e uma maior colaboração interdisciplinar levou ao florescimento das 'humanidades digitais', mas também levou a apelos para que se fizesse uma melhor articulação e definição do que são 'humanidades digitais'." Os autores não se isentam da tarefa que propõem e, em seguida, oferecem uma identidade claramente metodológica às humanidades digitais. A ênfase na metodologia levou alguns autores a sugerir o conceito de "comunidade de práticas" ao universo das humanidades digitais, posição assim sintetizada por William G. Thomas III:

Muitos acadêmicos nas humanidades digitais começaram a se ver, e a agir, como uma comunidade aberta de práticas, incorporando a todos cuja energia, expertise e entusiasmo se alinhassem aos deles. Ao invés de conceberem um projeto que demandasse uma disciplina ou campo à parte, as humanidades digitais trabalharam dentro das disciplinas a partir de um conjunto vagamente definido de métodos comuns, todos implicados num amplo reconhecimento: que compreensão e pesquisa humanísticas estavam sendo reconstituídas em formato digital por meio de tecnologias digitais. (Thomas III, 2016: 526-527) 
A priorização da metodologia pode levar à atribuição de um caráter tático e provisório às humanidades digitais, perspectiva que Andrew Prescott sintetiza desta forma: " [...] é mais provável que técnicas digitais se tornem tão comuns em outras disciplinas, que se venha a questionar a função das humanidades digitais em quanto [sic] atividade à parte". ${ }^{3}$ Posição diametralmente oposta a essa é a defendida por Patrik Svenson (2016: 79), que assume um tom prescritivo e quase programático na direção da instituição disciplinar das humanidades digitais, o que o aproxima de Claire Warwick (2016), que compara a trajetória a ser perseguida nessa direção com o percurso histórico de duas disciplinas tradicionais e amplamente reconhecidas: história e "English studies", que teriam enfrentado as mesmas ambiguidades, contradições, inseguranças e falta de reconhecimento institucional que hoje afetam as humanidades digitais.

Entre um Companion e outro, surgiu o já referido Debates in digital humanities (Gold, 2012). Se, em 2004, o primeiro Companion não trazia grandes problematizações identitárias, o Debates, de $2012^{78}$, já teve a necessidade de dedicar toda a primeira parte do livro à tentativa de definir as humanidades digitais. ${ }^{4}$ Ainda que boa parte dos artigos ali coligidos refletisse a perspectiva pretensamente inclusiva das humanidades digitais, sintetizada na ideia de " big tent ${ }^{\prime \prime}{ }^{5}$ as diversas posições não discrepavam, no conjunto, do que foi sintetizado a partir do New companion, com direito a proposições mais extremas, como aquela contida no texto "There are no digital humanities" (Hall, 2012). A nova edição dos Debates, de 2016, apenas confirmou a impossibilidade do consenso. Já em sua introdução, Lauren Klein e Matthew Gold (2012) resumem assim o que chamam de "dilema definitório": "No que já foi chamado de 'big tent' $\mathrm{DH}$, pode por vezes ser difícil determinar de modo minimamente específico o que implica, precisamente, o trabalho em humanidades digitais."

Portanto, não se sabe ao certo o que sejam as humanidades digitais, e nada aponta para que se saiba em futuro próximo. Por outro lado, se não há esse consenso, é forçoso reconhecer que alguma "identidade operante" existe. Em outras palavras, a própria existência do debate, assim como dos fóruns e dos veículos em que acontece, sem mencionar os diversos graus de institucionalização que as humanidades digitais alcançaram, estão a indicar que o conceito é capaz de um nível considerável de agregação de expectativas e de, por conseguinte, condicionar muitas interlocuções produtivas, na academia e fora dela.

Este artigo não pretende responder à questão do que sejam as humanidades digitais, nem mesmo trazer argumentos que corroborem ou questionem diretamente as várias posições aqui reconhecidas. Mas isso não significa que estas linhas não busquem trazer elementos que ajudem no debate. Ao oferecer o relato e algumas reflexões acerca de experiências desenvol- 
vidas no âmbito do Departamento de História da Universidade Federal de São Paulo (Unifesp), a pretensão é enriquecer o universo empírico sob análise. Se é verdade que "humanidades digitais é o que fazem os humanistas digitais", na formulação de tom kuhniana de R. Alvarado (apud Robertson, 2016: 289), conhecer e debater as experiências concretas em salas de aula e laboratórios, reconhecendo idiossincrasias e identidades, pode ser de grande ajuda. De resto, ao fazê-lo no escopo de uma edição especial de uma revista brasileira de referência, pretende-se colaborar também para uma configuração menos eurocêntrica das humanidades digitais.

0 que se escolheu apresentar aqui procura abarcar duas perspectivas diferentes no que diz respeito ao lugar institucional a partir do qual as iniciativas foram realizadas: um grupo de pesquisas e uma disciplina de graduação.

\section{O GRUPO HÍMACO}

- m agosto de 2010, foi criado o grupo de pesquisas Hímaco - História, Mapas e Computa— dores, junto ao Departamento de História da Unifesp, pelos professores Luis Ferla e Janes Jorge. ${ }^{6}$ Seu objetivo era, e é, explorar as possibilidades das geotecnologias em investigações históricas. A iniciativa pretendia responder à percepção de que as tecnologias digitais já representavam uma realidade incontornável para o historiador, e que sua presença no ambiente acadêmico deveria dar-se de forma a mais precoce e refletida possível. Nesse sentido, o grupo pretendia constituir uma base para incursões exploratórias mais sistemáticas ao território das tecnologias digitais, ao mesmo tempo que buscava refletir sobre seus impactos metodológicos e epistemológicos no trabalho do historiador. Em seus primeiros tempos, o grupo dedicou-se muito mais ao segundo objetivo, dado que não tinha ainda capacitação e infraestrutura tecnológicas para projetos de pesquisa propriamente ditos que tivessem essa identidade. Mas é evidente que a discussão teórica de impactos práticos da utilização da tecnologia digital em investigações históricas apresentava um desequilíbrio incômodo.

Tratava-se, então, de buscar constituir um espaço dotado com equipamentos e softwares, operado por uma equipe minimamente capacitada para tal. Em outras palavras, o Hímaco necessitava de um laboratório e de conhecimento para utilizá-lo. Àquela época, o campus de humanidades da Unifesp, criado em 2007 e localizado em Guarulhos, ainda era bastante precário, carente de muitas instalações básicas para seu funcionamento. O laboratório do Hímaco não estava em suas prioridades. A solução estaria, portanto, na busca de cooperações com órgãos afins de fora da universidade. Em 2011, foi estabelecida uma parceria com o Núcleo de Acervo Cartográfico do Arquivo Público do Estado de São Paulo (Apesp). Em dezembro de 2012, a parceria foi oficializada com a assinatura de convênio respectivo (renovado sucessiva- 
mente em 2016 e em 2018). A colaboração com o Apesp permitiu ao Hímaco não apenas um espaço privilegiado de trabalho, como a interação com parte de seu pessoal técnico, dando ao grupo um ganho de interdisciplinaridade que seria uma marca de seu percurso desde então. A professores e graduandos em história da Unifesp juntavam-se geógrafos e graduandos em geografia, funcionários e estagiários do Apesp.

O grupo enriquecia sua composição e conseguia um espaço para trabalhar. No entanto, faltavam ainda software, hardware e capacitação para manuseá-los na direção dos objetivos do grupo. Dessas carências, foi à primeira que se deu solução mais imediata, oferecida pela alternativa das tecnologias livres. Os programas proprietários de sistemas de informações geográficas (SIGS) são caros e de reprodução restrita. Já com relação aos softwares livres, sabe-se que, desde 1999, quando o software Grass adotou uma licença aberta, "seu aprimoramento e sofisticação os têm colocado cada vez mais ao nível dos melhores softwares proprietários, tanto no que se refere às potencialidades de seus recursos como ao caráter 'amigável' de suas interfaces, com todas as vantagens inerentes à aquisição gratuita e à livre reprodução" (Ferla et al., 2016: 86).

Por conta disso, foi feita a opção pelo gvSIG, software livre surgido em 2004 na Espanha e que conta hoje com uma comunidade de usuários bastante difundida internacionalmente. O grupo Hímaco utiliza o gvSIG desde 2011, e a experiência tem sido bastante satisfatória. Registre-se que uma pretensa desvantagem referente à falta de uma estrutura de suporte que o software proprietário fornece não existe de fato, pois a comunidade de usuários mantém listas de discussões bastante ativas e eficientes para a resolução de problemas. Por outro lado, há bastante identidade entre o grupo Hímaco e o projeto gvSIG, na ênfase da defesa da livre circulação do conhecimento e do trabalho colaborativo. Por conta disso, foi feita a opção pelo gvSIG, software livre surgido em 2004 na Espanha e que conta hoje com uma comunidade de usuários bastante difundida internacionalmente. 0 grupo Hímaco utiliza o gvSIG desde 2011, e a experiência tem sido bastante satisfatória. Registre-se que uma pretensa desvantagem referente à falta de uma estrutura de suporte que o software proprietário fornece não existe de fato, pois a comunidade de usuários mantém listas de discussões bastante ativas e eficientes para a resolução de problemas. Por outro lado, há bastante identidade entre o grupo Hímaco e o projeto gvSIG, na ênfase da defesa da livre circulação do conhecimento e do trabalho colaborativo. ${ }^{7}$ Foi também em conformidade com tais princípios que o grupo foi capacitado no manuseio do software, em curso ministrado voluntariamente por um membro da comunidade brasileira do gvSIG, em maio e junho de 2011.8 Posteriormente, e com mais experiência e conhecimento, o grupo elaborou e publicou em seu site um "Tutorial de gvSIG básico aplicado 
a estudos históricos" (Moraes et al., 2014). ${ }^{9}$ Ainda que o programa tenha muitas versões de manuais disponíveis na internet, essa é a primeira vez que aparece um material mais adequado aos historiadores e às suas fontes. Ressalte-se também que o tutorial foi elaborado com a participação de todo o grupo, mas com a coordenação sucessiva de alunos bolsistas BIG (Bolsa de Incentivo à Gestão) da Unifesp. Ou seja, trata-se de um material em constante aprimoramento e que teve, e tem, o principal suporte para sua elaboração na atuação de alunos de graduação. Por fim, a publicação do tutorial não apenas auxiliou significativamente na difusão da tecnologia junto às comunidades envolvidas, como permitiu uma considerável economia de energia do grupo em atividades de treinamento.

Já com relação à aquisição dos computadores e equipamentos necessários, havia de se buscar financiamentos junto às agências de fomento. $E$, para isso, fazia falta um projeto de pesquisa. ${ }^{10}$ Em 2012 e 2013, o grupo conseguiu financiamentos junto ao Conselho Nacional de Desenvolvimento Científico e Tecnológico (CNPq) e à Fundação de Amparo à Pesquisa do Estado de São Paulo (Fapesp) para o projeto "Implementação da tecnologia de sistemas de informações geográficas (SIG) em investigações históricas".

A opção pelos sistemas de informações geográficas, já dada com a capacitação no uso do gvSIG, reforçava-se pelo suporte da bibliografia, que reconhecia, entre as várias tecnologias crescentemente disponíveis às humanidades digitais, a primazia dos SIGs entre os historiadores (Gregory e Ell, 2007: 17-18). Tal preferência certamente tem relação com as possibilidades que a tecnologia oferece para reconhecer uma posição mais privilegiada da dimensão espacial nos estudos do passado.

Para atingir o objetivo colocado, foi proposto um estudo-piloto que permitisse a articulação entre prática e teoria, fazendo as vezes de metodologia no projeto mais geral. Com o suporte dos conhecimentos especializados de alguns dos professores envolvidos, chegou-se ao projeto "As enchentes na cidade de São Paulo: abrangência espacial e impactos sociais (1870-1940)". ${ }^{11}$ Seu objetivo era identificar as principais enchentes da história da cidade em seu período de urbanização e modernização industrial e produzir visualizações espaciais de seu alcance. As enchentes mapeadas foram as de 1887 e de 1929. A primeira foi uma das maiores que a cidade vivenciou (Kogan, 2013). As águas, que subiam periodicamente nos meses mais quentes do ano, começaram a encontrar as ruas da cidade quando esta passou a experimentar um crescimento urbano formidável, nas últimas décadas do século XIX. Nesse sentido, essa enchente é um marco importante na história da cidade, pois pode ser considerada um emblema da transformação das "cheias" (elevação natural e cíclica do nível das águas) em "enchentes" (encontro das cheias com a urbanização). 
Já a enchente de 1929

[... foi considerada pelos contemporâneos e, depois deles, pelos estudiosos da história urbana paulistana a maior inundação que a cidade de São Paulo conheceu. Embora essa avaliação não seja, em si mesma, polêmica, as suas causas foram objeto de divergência, tanto na época em que ela ocorreu como nos dias de hoje. De todo modo, prevalece na bibliografia especializada a interpretação de que [...] a altura das águas não teria alcançado o nível que alcançou não fosse a abertura das comportas da represa do Guarapiranga pela Light, Tramway \& Power Ltd., com objetivos de aumentar seus ganhos econômicos. (Santos et al., 2014: 150)

Apesar dessa importância historiográfica indiscutível, a enchente de 1929 não tinha ainda uma representação cartográfica de seu alcance espacial, o que o projeto do Hímaco produziu e disponibilizou. ${ }^{12}$

No que diz respeito ao percurso do Hímaco, o projeto permitiu tanto a capacitação tecnológica do grupo no uso das geotecnologias em pesquisas históricas quanto a estruturação material de seu laboratório no Apesp, por meio dos financiamentos obtidos.

\section{O LAB.HUM}

- m junho de 2016, os equipamentos do Hímaco foram transferidos do Apesp para o recém— -criado lab.hum - Laboratório de Humanidades Digitais da Unifesp, nas novas dependências do campus Guarulhos da Unifesp, inauguradas naquele período. 0 lab.hum tem o objetivo de congregar e viabilizar atividades de pesquisa, ensino e extensão que tenham relação com as humanidades digitais e produzir reflexões acerca de seus impactos.

Por se tratar de um espaço interdepartamental daquele campus, participam outros quatro grupos de pesquisa da unidade. ${ }^{13}$ Por sua vez, e em atendimento à renovação do convênio com a Unifesp, o Apesp manteve o espaço destinado ao grupo e decidiu reequipá-lo com computadores da instituição. A partir de então, o espaço no Apesp passou a priorizar a interlocução com pesquisadores daquela e de outras instituições, ao passo que o lab.hum é utilizado principalmente para as atividades cotidianas do grupo e para intensificar suas relações com o alunado da Unifesp.

\section{O Projeto PAuliceia 2.0}

avendo encerrado de forma satisfatória seu primeiro projeto de pesquisa ${ }^{14}$ e tendo alcan-
çado um novo patamar de capacitação e de consolidação institucional e de infraestrutura, o Hímaco desenvolveu, então, uma proposta mais ousada: o mapeamento colaborativo da história da cidade de São Paulo, de 1870 a 1940. 0 caráter pioneiro e complexo do projeto ${ }^{15}$ 
principalmente por envolver questões computacionais de monta, deixava claro desde o início que as parcerias do grupo teriam de ser ampliadas. A oportunidade surgiu em 2015, quando foi publicada a segunda chamada do Programa eScience, da Fapesp, destinado a fomentar pesquisas que envolvessem as ciências da computação e outras áreas de conhecimento. ${ }^{16} \mathrm{Com}$ o suporte desse edital, foi montada uma equipe multi-institucional e interdisciplinar para construir e apresentar um projeto que viabilizasse o mapeamento colaborativo ideado pelo Hímaco. ${ }^{17}$ Aos membros do Apesp e do campus Guarulhos da Unifesp juntaram-se pesquisadores do Instituto de Ciência e Tecnologia do campus São José dos Campos da mesma universidade, do Instituto Nacional de Pesquisas Espaciais (Inpe) e da Emory University, dos Estados Unidos. ${ }^{18}$ A coordenação do projeto ficou sob a responsabilidade de Luis Ferla, da Unifesp, com a cocoordenação de Karine Reis Ferreira, do Inpe. Em setembro de 2016, a proposta foi uma das cinco contempladas pela chamada ${ }^{19}$, e o início da vigência do financiamento deu-se em fevereiro de 2017.

Em 4 de abril de 2017, o projeto foi apresentado em evento no auditório do Arquivo do Estado. Em conformidade com os preceitos da chamada ciência aberta, ${ }^{20}$ a ideia era discutir com a comunidade potencial de usuários da plataforma, pesquisadores da história de São Paulo no período proposto, críticas e sugestões ao projeto, além de solicitar material empírico de pesquisa para dar suporte aos testes no desenvolvimento dos códigos computacionais necessários. ${ }^{21}$ Já em 30 de outubro de 2018, outro evento, no mesmo local, teve o objetivo de apresentar a versão beta da plataforma (<www.pauliceia.dpi.inpe.br>) e convidar a comunidade a ajudar a testá-la. ${ }^{22}$

0 projeto encontra-se, atualmente, na fase de aprofundamento dos testes e de amadurecimento tecnológico, ao mesmo tempo que se busca o estreitamento da interlocução com a comunidade-alvo. Além disso, a área espacial em que o geolocalizador da plataforma opera está sendo ampliada, pois na primeira fase apenas uma área-piloto foi contemplada, correspondente ao centro da cidade. Os resultados até aqui alcançados podem ser verificados na própria plataforma, obviamente, e no artigo de Gomes et al. (2018).

\section{WIKIPÉDIA NA UNIVERSIDADE E O ENSINO DE HISTÓRIA MODERNA}

S a trajetória do grupo Hímaco demonstra um movimento da pesquisa em direção à extendesde a docência. Segundo a Constituição de 1988 (artigo 207), a principal característica das universidades, para além de "gozarem de autonomia didático-científica, administrativa e de gestão financeira e patrimonial", é a de obedecer "ao princípio de indissociabilidadade 
entre ensino, pesquisa e extensão". Se há muito que se regulamenta o quanto as instituições públicas de ensino devem ministrar de carga horária, e se cobra, por meio dos programas de pós-graduação, certos níveis de pesquisa acadêmica, até muito recentemente não houve uma preocupação de regulamentar claramente a intensidade de atividades de extensão efetuadas pelos docentes, apesar de estas serem objeto de avaliação das carreiras. A Unifesp adiantou-se ao Ministério da Educação (MEC) e, em resolução de 11 de outubro de 2017, decidiu que seus cursos de graduação deveriam assegurar um mínimo de 10\% de sua carga horária total em atividades de extensão. ${ }^{23}$ Essa resolução está ainda em fase de implementação, e existe pouca clareza nos tipos de atividades que podem ser enquadrados nos parâmetros de curricularização dos projetos de extensão no nível da graduação.

Tomando como exemplo experiências e reflexões a partir de projetos pioneiros sobre o uso da Wikipédia como atividade de extensão e de ensino em cursos de graduação, como o aplicado no curso de história antiga da Universidade Federal do Estado do Rio de Janeiro (Unirio) (Marques, 2013), bem como uma proposta mais ampla de "wikipedagogia", levada adiante no curso de jornalismo da Faculdade Casper Líbero (Moraes et al., 2016), a área de história moderna da Unifesp começou um projeto, parcialmente financiado por meio de bolsas do Programa de Monitoria da Unifesp, para trabalhar com a Wikipédia em sala de aula. Em fase de experimentação, desde o segundo semestre de 2018, a área tem utilizado como método de ensino e avaliação a edição de verbetes da enciclopédia virtual Wikipédia nas duas unidades curriculares semestrais (História Moderna I e II), nas quais a área se divide, cronologicamente, na matriz curricular do curso de história.

Desse ponto de vista, a atividade pretendeu ser uma interface entre as humanidades digitais e a extensão e coadunar o interesse do aluno pelas plataformas digitais ${ }^{24}$ e sua visibilidade, com as necessidades de atuação junto a setores extrauniversitários. Assim, mais do que a exatidão do conteúdo (obviamente, essa era necessária), o que se buscou fomentar nos diferentes grupos de alunos foi uma melhor forma de comunicação de conhecimento acadêmico e seu referenciamento para o público geral. Houve o apoio imprescindível de um grupo de monitores, que atuou tanto no segundo semestre de 2018 quanto no primeiro de 2019. Além disso, houve o suporte da equipe brasileira ligada à Wikimedia Foundation, João Alexandre Peschanski, na formatação do projeto inicial, e Célio Costa Filho, que, antes do começo das atividades, ministrou aos alunos palestra sobre o que era a Wikipédia, mostrando igualmente os passos básicos de edição. Foi também por meio da equipe Wikimedia que os docentes familiarizaram-se com o uso do outreach dashboard (painel de controle externo) da Wikipédia, ferramenta de ensino que lhes permite acompanhar a atuação das turmas em seu trabalho de edição dos verbetes, ao congregar em uma única página todos os usuários e verbetes em edição de um projeto (Figuras 1 e 2). ${ }^{25}$ 


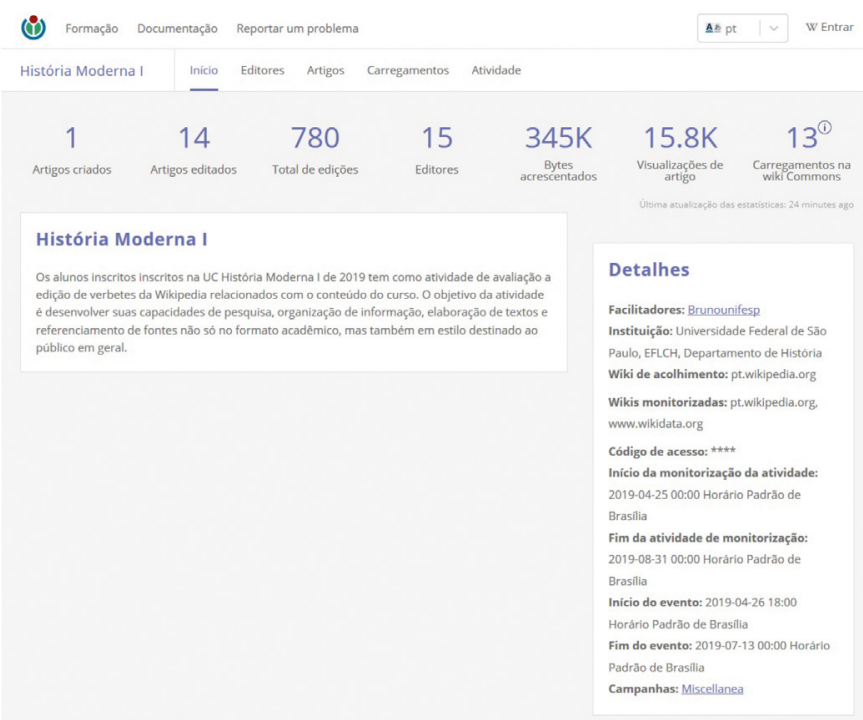

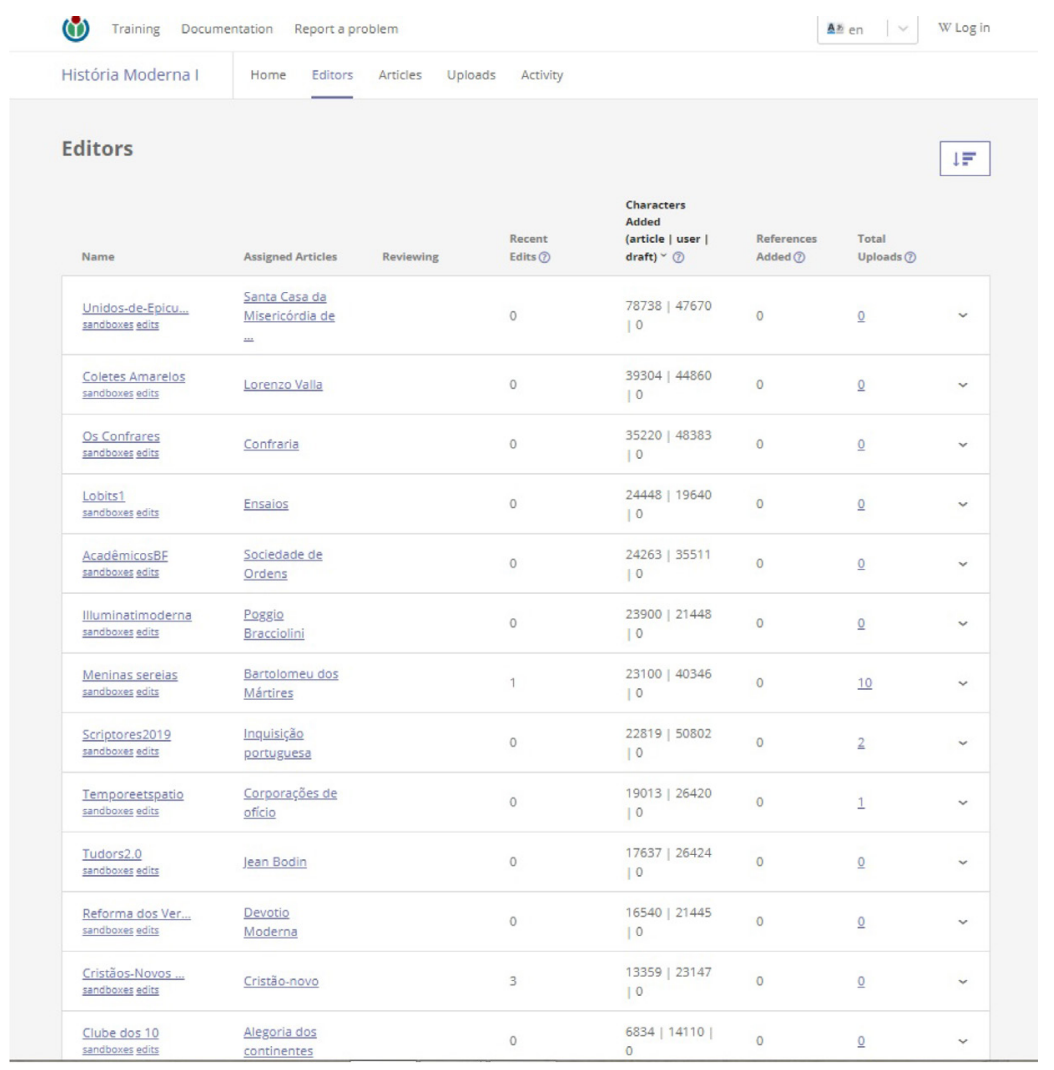

Figuras 1 e 2 - Página de abertura e listagem dos grupos no dashboard de História Moderna I. 
No segundo semestre de 2018, foi realizada uma primeira experiência com a Wikipédia nas turmas de História Moderna II. Sendo uma primeira incursão, definiu-se com a turma do vespertino que se trabalharia somente com quatro verbetes, editados por quatro grupos sob supervisão dos monitores da turma, e com a turma do noturno que esta trabalharia coletivamente com a criação de um verbete a ser criado. Isso permitiria testar duas modalidades de uso e interação com a plataforma Wiki, a partir das indicações de experiências feitas nas palestras da equipe da Wikimedia. Na turma da tarde, sob supervisão do professor Luís Filipe S. Lima, os verbetes foram selecionados entre aqueles que estavam indicados como "esboço" ou que precisavam de "revisão", segundo a classificação da própria Wikipédia. Houve a preocupação de não se fazer terra arrasada do que já havia, mas aproveitar o existente (mesmo quando muito pouco), para a partir dali construir o verbete com o que se produziu e se discutiu em sala de aula. Os verbetes do vespertino foram: Fronda, Guerra de Sucessão Espanhola, Restauração, Revolução Gloriosa. Na turma da noite, sob supervisão do professor Maximiliano Menz, os estudantes trabalharam com a criação do verbete (inexistente até então) sobre a Crise Geral do Século XVII. ${ }^{26}$

Já na primeira experiência, os resultados foram bastante positivos, e a recepção das turmas, também. Os verbetes, quando publicados, ainda não estavam perfeitos, especialmente no que se referia à redação e à precisão de alguns termos, processos e informações. Entretanto, alguns números mostram o trabalho realizado em termos bastante impressionantes (Figura 3): foram mais de 127 mil caracteres editados (soma de tudo trabalhado ao longo do semestre), o que resultou, somando os quatro verbetes, em mais de 22 mil palavras espalhadas em 60 laudas ou 61 páginas do Word. 0 maior verbete, aquele sobre a Restauração, tem agora 7 mil palavras ou 23 páginas. Em termos de visitação, entre dezembro de 2018 (quando foram ao ar) e 31 de janeiro de 2019 (quando o dashboard de Moderna II parou de computar os dados), os verbetes tiveram mais de 59 mil visitas no total (variando de 1.138, verbete "Fronda", até 32.809 visitas, verbete "Revolução Gloriosa"). 


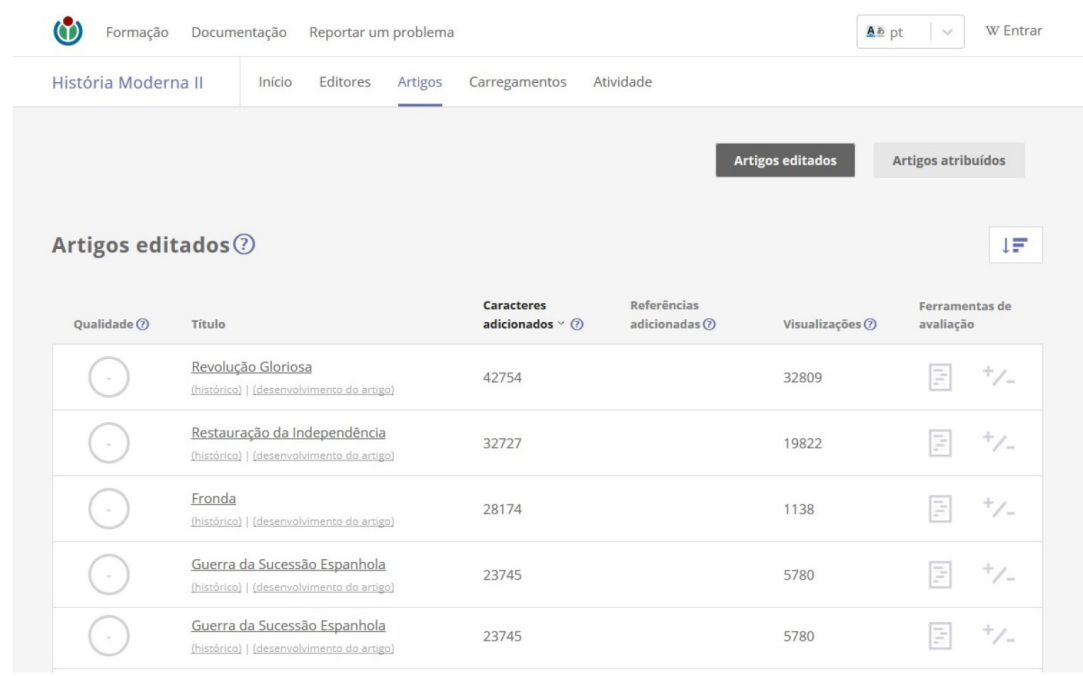

Figura 3 - Página do dashboard de História Moderna II, com os dados referentes aos quatro verbetes trabalhados.

No caso dos alunos de História Moderna I (primeiro semestre de 2019), as turmas foram divididas em grupos de 10 alunos, que deviam, cada um, criar no portal um login único, e a cada grupo foi designado um verbete que estivesse em forma de esboço (como no caso do "Ensaios ${ }^{10 "}$ ", de Michel de Montaigne) ou em carência de referências (como "Inquisição Portuguesa"). ${ }^{27}$ Durante três semanas, uma parte da aula era reservada para que o docente e os monitores solucionassem dúvidas dos alunos quanto à escolha de bibliografia, à compartimentação do texto no verbete ou ao modo de referenciar as fontes. Na última aula do semestre, foi organizado um seminário, no qual os grupos apresentaram seus verbetes, não pelo conteúdo, mas do ponto de vista metodológico. Apresentava-se o estado inicial do verbete com os problemas encontrados e as soluções que o grupo aplicou a cada caso específico, buscando-se chamar a atenção para as necessidades de adequação de conteúdo, formato e vocabulário, dependendo do suporte e do público-alvo. Foram poucos os alunos que se queixaram, no fim do percurso, de dificuldades em manejar a inserção de dados ou referências na plataforma, graças à mencionada palestra introdutória e à diligência dos já experientes tutores.

0 interesse do ponto de vista da extensão vincula-se ao fato de a plataforma permitir um rápido retorno do público, já que a Wikipédia é aberta à edição por todos, conforme definido pelo terceiro de seus "cinco pilares" de funcionamento (Marques et al., 2013: 71-72). Como a Wikipédia é uma plataforma dinâmica, aberta e colaborativa, os verbetes já receberam correções, edições, adições e, provavelmente, sofrerão modificações nos próximos tempos. Isso é positivo do ponto de vista extensionista do projeto, pois significa que o trabalho dos 
grupos não só será melhorado, mas também que levará a outro patamar as informações a serem trabalhadas sobre esses tópicos. Mais do que isso, essa dinâmica colaborativa obriga a pensar ensino e produção de conhecimento histórico em sala de aula e na universidade de outras maneiras, refletindo sob a forma como se comunica e submetendo o que se produz a um público mais amplo e variado, bem como a um escrutínio de uma legião de pessoas de fora do meio acadêmico que frequenta, edita e contribui para a Wikipédia. ${ }^{28}$ Nesse sentido, é também uma experiência de extensão, na medida em que não só "leva" o conhecimento para além dos muros (aqui virtuais) da universidade, mas também faz com que se parta do que já existe como conhecimento na plataforma, ao mesmo tempo que se coloca o produzido na universidade à disposição de quem quiser retificá-lo, discuti-lo ou disputá-lo. Não se trata só de corrigir algum conteúdo de verbete ou completar referências deficientes, mas de colaborar com a produção de um conhecimento que será usado e ampliado de modo extensivo, e que não obedece nem segue as lógicas de autoridade da academia.

\section{ALGUMAS REFLEXÕES E CONCLUSÕES POSSÍVEIS}

Como afirmado no início, a experiência que tal percurso proporcionou pretende ser um estímulo à reflexão sobre a relação entre as tecnologias digitais e o ofício do historiador. Assim, não é pretensão do artigo dar conta de responder ao que sejam as humanidades digitais. Mas, se o exposto servir de suporte para a análise, é possível que saia reforçada a ideia de que as humanidades digitais sejam uma comunidade de práticas, pois essa identidade pode ser assumida por dois projetos de características, objetivos e origens diferentes. Se o grupo Hímaco sempre desenvolveu suas pesquisas buscando refletir prioritariamente sobre o papel das tecnologias nelas, o projeto que trabalhou com a Wikipédia tinha o centro de sua preocupação em otimizar o alcance do conhecimento produzido e capacitar os estudantes para fazê-lo. No entanto, o que foi relatado pode colaborar para definir ou corroborar outras características compartilhadas por tal comunidade, para além do uso das tecnologias em seu trabalho.

Uma contribuição que talvez seja algo original ao debate é o reconhecimento do papel fundamental que podem ter os alunos de graduação nos projetos de humanidades digitais, como se dá nas experiências aqui apresentadas. Tanto nas iniciativas do grupo Hímaco quanto nos projetos da disciplina de história moderna com a Wikipédia, o ator central é o graduando. Pode-se interpretar tal protagonismo não apenas pela maior familiaridade das novas gerações com as tecnologias digitais, como também pelo fato, a princípio paradoxal, da pouca curricularização das humanidades digitais, ao menos na grande maioria das universidades brasileiras (Rodrigues, 2018). Se o primeiro fator favorece a aproximação dos alunos aos projetos mais 
tecnológicos nas áreas de humanas, o segundo diminui a presença neles de pós-graduandos. Como a grande maioria dos alunos termina a graduação com muito pouca ou frequentemente nenhuma interação mais dedicada às humanidades digitais, é natural que as pesquisas que apresentam nos processos seletivos tratem de temas mais tradicionais da produção historiográfica. Por outro lado, e assumindo mais uma vez uma perspectiva kuhniana, é razoável supor que os alunos de graduação estejam menos condicionados por paradigmas estabelecidos e, assim, mais afeitos a participar de projetos mais heterodoxos. 0 fato é que, pelas experiências aqui compartilhadas, pode-se constatar que os alunos de graduação têm uma capacidade de criação e investigação ainda subestimada nos ambientes universitários.

Por outro lado, os paradigmas de avaliação e valorização do trabalho docente seguem bastante inflexíveis aos impactos das tecnologias digitais. Projetos de humanidades digitais, justamente voltados à maior circulação do conhecimento produzido, como são aqueles aqui discutidos, têm peso insignificante nos critérios avaliativos de produtividade em quase todas as instâncias pertinentes, sejam aquelas internas às universidades, sejam aquelas ligadas a agências de fomento e órgãos governamentais voltados à educação e à pesquisa. Ainda que a interdisciplinaridade e a abertura científica associadas às humanidades digitais sejam reiteradamente valorizadas nesses ambientes no plano discursivo, pouco disso se reflete nas avaliações do que é produzido nas universidades. É evidente que essa situação tende a desestimular os trabalhos na área. A bibliografia já acumula reflexões importantes sobre o problema, fazendo da experiência na Unifesp apenas mais um exemplo a reforçar o desconforto. ${ }^{29}$

Mas, se há dificuldades em valorizar institucionalmente os resultados concretos dos trabalhos em humanidades digitais, esses têm o potencial de dar à universidade ganhos significativos em impacto social. Uma das conclusões possíveis da experiência aqui relatada não destoa de certo consenso entre os estudiosos do tema: a afinidade entre os projetos de humanidades digitais e as práticas colaborativas e de livre circulação do conhecimento. Aqui se impõe uma aproximação entre os conceitos de extensão universitária, história pública e ciência aberta. Em comum, o questionamento das fronteiras tradicionais que separam o mundo dos produtores de conhecimento de seus "consumidores".$^{30}$ Talvez o mais correto seja colocar tal fenômeno em perspectiva histórica e associá-lo à própria afirmação da vida moderna, como já apontava Walter Benjamin em texto clássico de 1936:

Durante séculos, houve uma separação rígida entre um pequeno número de escritores e um grande número de leitores. No fim do século passado, a situação começou a modificar-se. (...) Com isso a diferença essencial entre autor e público está a ponto de desaparecer. Ela se transforma numa diferença funcional e contingente. A cada instante, o leitor está pronto a converter-se num escritor (Benjamin, 1996: 184). 
Benjamin se referia às cartas de leitores de jornais de fins do século XIX. Mas, se esse processo tem, portanto, uma longevidade bem maior do que o fascínio ou a perplexidade, com as novas tecnologias digitais sugerem, há de se reconhecer que o novo século acelerou dramaticamente as possibilidades de autoria do cidadão comum. Muitos sintetizam essas novas possibilidades no conceito de web 2.0, que se diferenciaria de sua versão anterior pelo caráter bidirecional de seus fluxos, não mais apenas opondo os criadores de webpages a seus leitores e consulentes, mas permitindo que estes também produzam conteúdo. As chamadas redes sociais, e sua difusão explosiva desde a primeira década deste século, seriam a demonstração emblemática do triunfo da web 2.0. É evidente que tal processo não teria como não impactar fortemente o mundo acadêmico e os regimes de produção do conhecimento científico. Não cabe aqui um inventário exaustivo desse impacto, ${ }^{31}$ mas deve ser destacada a enorme facilitação do trabalho colaborativo e da atuação de agentes e comunidades extrauniversitárias no acesso e na produção do conhecimento científico. Por outro lado, e por consequência direta do questionamento dessa fronteira tradicional, a universidade perde crescentemente o lugar identificado com o monopólio da criação do saber legitimado. Antes que negar o fenômeno e, assim, aprofundar seu isolamento social, alternativas mais inteligentes se oferecem à academia. Por exemplo, seu lugar permanece privilegiado para dirigir e organizar a interlocução entre os "mundos de fora e de dentro da universidade". Nesse sentido, sua atuação teria também muito de curadoria, para além, evidentemente, de continuar produzindo conhecimento, sem o que perderia grande parte da razão de sua existência. Os projetos aqui discutidos são uma expressão característica desse fenômeno à escala de um campus de humanas de uma universidade pública brasileira.

\section{NOTAS}

1 Ver, por exemplo, Gil (2016) e O'Donnell et al. (2016). Algumas iniciativas lidam com a questão com mais prioridade, como é o caso do Global Outlook: Digital Humanities (Disponível em: <http://www.globaloutlookdh.org >. Acesso em: 6 fev. 2019), grupo ligado à Alliance of Digital Humanities Organisations (ADHO); e a série de dossiês em idiomas latinos que a Digital Humanities Quarterly vem organizando (Disponível em: $<$ http://www.digitalhumanities.org/dhq>. Acesso em: 6 fev. 2019).

2 Desse e de outros excertos de obras em inglês, a tradução é dos autores, e todas as ênfases foram adicionadas.

3 Ainda que o autor admita que: "Sempre haverá necessidade de novos desenvolvimentos pioneiros na interseção de humanidades e tecnologia da informação, e é sem dúvida neste tipo de trabalho científico pioneiro que se encontra uma parte importante da futura missão das humanidades digitais" (Prescott, 2016: 473).

4 Entre os autores, reencontramos Patrik Svenson (2012), reapresentando as humanidades digitais como "local de encontro" ou "zona de negociação", conforme conceito de Peter Galison. 
5 "Big tent digital humanities" foi o tema da Digital Humanities Conference, realizada em 2011 na Stanford University (Disponível em: <http://dh2011.stanford.edu>. Acesso em: 5 fev. 2019).

6 Cadastradojuntoao CNPqdesde2011 (Disponívelem:<dgp.cnpq.br/dgp/espelhogrupo/3777602011014869>).

7 Ao ponto de o Hímaco ser reconhecido como "sócio honorário" da Associação gvSIG (Disponível em: $<$ http://www.gvsig.com/pt/associacao-gvsig/membros-de-honra>. Acesso em: 29 jul. 2019). Além disso, o Hímaco participou ativamente da organização de duas jornadas de usuários na cidade de São Paulo (III Jornadas Brasileiras de gvSIG, em 2012; e 6as Jornadas Latino-Americanas e do Caribe de gvSIG, em 2014).

80 instrutor convidado foi Guilherme Bagattini, da Secretaria de Meio Ambiente da Prefeitura de Guarulhos e membro da comunidade brasileira do gvSIG. Realizado nas dependências da Unifesp e do Apesp, o curso teve carga horária de 32 horas.

9 Disponível em: <http://www2.unifesp.br/himaco/pdf/Tutorial_Himaco_1_11_Branco.pdf>. Acesso em: 29 jul. 2019.

10 Aqui, reconhece-se uma idiossincrasia do grupo: ao contrário do que é mais corrente, não se tinha um problema científico em busca da tecnologia para resolvê-lo, mas precisamente o oposto.

11 Os professores Janes Jorge e Fábio Alexandre dos Santos, membros da equipe do projeto, têm estudos e publicações acerca das relações entre corpos d'água e urbanização. Ver, por exemplo, Jorge (2006) e Santos (2011).

12 Esse e outros resultados do projeto, assim como toda a documentação que lhe deu suporte, encontram-se disponíveis no site do grupo (<www.unifesp.br/himaco>) e no artigo Santos et al. (2014).

13 São eles: o CAPPH (Cidade, Arquitetura e Preservação em Perspectiva Histórica); o Gesua (Grupo de Estudos Sociais, Urbanos e Ambientais); o Pimentalab (Laboratório de Tecnologia, Política e Conhecimento); e o Visurb (Grupo de Pesquisas Visuais e Urbanas).

14 No mesmo período em que foi desenvolvido o projeto-piloto, alguns membros do grupo participaram também do Projeto Pipag - Projeto de Inventário e Pesquisa Arqueológica de Guarulhos, coordenado pela professora Cláudia Plens. A atribuição desses no projeto foi justamente fazer o mapeamento do patrimônio inventariado. Os resultados encontram-se sintetizados e discutidos no dossiê do projeto, publicado na Revista do Museu de Arqueologia e Etnologia, da USP (Ferla et al., 2016. Disponível em: <http://www.revistas.usp.br/ revmae/article/view/119013>. Acesso em: 20 mar. 2018).

15 Apesar de ter um recorte espacial e temporal bastante diverso do que aqui se apresenta, deve ser mencionando o projeto coordenado pelo professor Tiago Gil, da Universidade de Brasília (UnB), intitulado "Atlas digital da América Lusa", por se tratar de uma iniciativa referencial de SIG histórico realizada no Brasil e que também valoriza o trabalho colaborativo e o compartilhamento do conhecimento (mais informações em: $<$ http://lhs.unb.br/biblioatlas/In\%C3\%ADcio>. Acesso em: 25 nov. 2019). Sobre a experiência do professor Gil e de sua equipe no desenvolvimento do projeto, ver Gil (2019).

16 Sobre o Programa eScience/Fapesp, consultar: <http://www.fapesp.br/8436> (Acesso em: 11 jul. 2019).

17 A equipe do projeto contava com 30 pessoas, sendo cinco doutores em história; quatro doutores em computação; um doutor em geografia; um doutorando em história; dois mestrandos em história; um mestrando em computação; duas bacharéis em história; uma engenheira civil; uma bacharel em geografia; uma arquiteta urbanista; seis graduandos em história; e cinco graduandos em computação. 
18 A integração de pesquisadores da Emory no projeto foi um dos resultados de outro programa da Fapesp, o Sprint - São Paulo Researchers in International Collaboration, que permitiu a viabilização de um intercâmbio entre pesquisadores da Unifesp e daquela universidade em reuniões em Guarulhos e em Atlanta, alinhavando a articulação entre os envolvidos na equipe do projeto (Disponível em: <http://agencia.fapesp.br/sprint-estimula-colaboracoes-internacionais-em-pesquisa/25035> e <https://global.emory.edu/support/news-events/ news/2017/february/fapesp-winners.html>. Acessos em: 13 jul. 2019).

19 Ver a lista de contemplados em www.fapesp.br/10487 acessado em 11 de julho de 2019).

20 Sobre o conceito de ciência aberta, ver Albagli et al. (2015).

21 Aqui, cabe um agradecimento especial às professoras Ana Lana e Sarah Feldman, da FAU/USP, que disponibilizaram à equipe do projeto seus dados de pesquisa.

22 Ambos os eventos tiveram transmissão ao vivo pelas redes sociais, e os vídeos respectivos podem ser acessados em: <https://www.facebook.com/arquivoestado/videos/1361653267206845/> e <https://www. facebook.com/arquivoestado/videos/704166923288544/> (Acessos em: 13 jul. 2019).

23 A Resolução n 139 do Conselho Universitário da Unifesp, de 11 de outubro de 2017, pode ser consultada em: <https://www.unifesp.br/reitoria/proex/images/PROEX/Curriculariza\%C3\%A7\%C3\%A3o/Resolucao139_curricularizacao.pdf> (Acesso em: 13 jul. 2019). A Resolução n 7, de 18 de dezembro de 2018, da Câmara de Educação Superior do MEC, em: <http://portal.mec.gov.br/index.php?option=com_docman\&view=download\&alias=104251-rces007-18\&category_slug=dezembro-2018-pdf\&ltemid=30192> (Acesso em: 13 jul. 2019).

24 Para uma discussão sobre os limites e as potencialidades dos recursos digitais no ensino de história e a geração dos chamados "nativos digitais", ver Rodrigues (2018: 149-155).

25 Os painéis de controle podem ser consultados em: <https://outreachdashboard.wmflabs.org/courses/Unifesp/Hist\%C3\%B3ria_Moderna_Il> e <https://outreachdashboard.wmflabs.org/courses/Universidade_Federal_de_S\%C3\%A30_Paulo,_EFLCH,_Departamento_de_Hist\%C3\%B3ria/Hist\%C3\%B3ria_Moderna_I/ home> (Acessos em: 13 jul. 2019).

26 Os verbetes podem ser acessados por meio dos painéis de controle, ou digitando-se seus títulos dentro do espaço de busca da plataforma da Wikipédia em português: <https://pt.wikipedia.org>.

27 Foram 12 os verbetes editados: Alegoria dos Continentes, Bartolomeu dos Mártires, Confraria, Corporações de Ofício, Cristão-novo, Devotio Moderna, Ensaios (de Montaigne), Inquisição Portuguesa, Jean Bodin, Lorenzo Valla, Poggio Bracciolini, Santa Casa de Misericórdia de Lisboa; e apenas um criado: Sociedade de Ordens.

28 Sobre algumas das implicações e dos limites da produção e divulgação do conhecimento histórico na Wikipédia, ver Rosenzweig (2006: 136-138).

29 Ver, por exemplo, Ramsay e Rockwell (2012) e Fitzpatrick (2012). A American Historical Association chegou a publicar um Guidelines for the professional evaluation of digital scholarship by historians, em junho de 2015 (Disponível em: <https://www.historians.org/teaching-and-learning/digital-history-resources/evaluation-of-digital-scholarship-in-history/guidelines-for-the-professional-evaluation-of-digital-scholarship-by-historians $>$. Acesso em: 28 nov. 2019).

30 Daí o neologismo "prosumer", proposto em artigo de 2012 (Burdick et al., 2012: 135). 
31 Por exemplo, não é tratado aqui o tema do estado de hipervigilância que as novas tecnologias permitem, em uma espécie de "lado escuro da lua" da web 2.0. Sob o impacto da atuação das grandes corporações de tecnologia no mundo acadêmico, ver Parra et al. (2018).

\section{REFERÊNCIAS BIBLIOGRÁFICAS}

ALBAGLI, S.; MACIEL, M. L.; ABDO, A. (Org.). Ciência aberta: questões abertas. Brasília: IBICT; Rio de Janeiro: Unirio, 2015.

BENJAMIN, W. A obra de arte na era de sua reprodutibilidade técnica. In: Obras escolhidas: magia e técnica, arte e política. São Paulo: Brasiliense, 1996.

BURDICK, A. et al. Digital_humanities. Cambridge/Londres: The MIT Press, 2012.

EDMOND, J. Collaboration and infrastructure. In: SCHREIBMAN, S.; SIEMENS, R.; UNSWORTH, J. (Ed.). A new companion to digital humanities. Malden: Blackwell, 2016.

FERLA, L.; OYAKAWA, K.; DINIZ, J.; FARIAS, O. Mapeamento SIG na pesquisa e inventário do patrimônio arqueológico de Guarulhos. Revista do Museu de Arqueologia e Etnologia, n. 26, 2016.

FIORMONTE, Domenico. Toward a cultural critique of digital humanities. In: GOLD, M.; KLEIN, L. (Ed.). Debates in the digital humanities. Minneapolis: University of Minnesota Press, 2016.

FITZPATRICK, K. Beyond metrics: community authorization and open peer review. In: GOLD, M. K. (Ed.). Debates in the digital humanities. Minneapolis: University of Minnesota Press, 2012.

FYFE, P. Eletronic errata: digital publishing, open review, and the future of correction. In: GOLD, M. K. (Ed.). Debates in the digital humanities. Minneapolis: University of Minnesota Press, 2012.

GIL, A. Interview with Ernesto Oroza. In: GOLD, M.; KLEIN, L. (Ed.). Debates in the digital humanities. Minneapolis: University of Minnesota Press, 2016.

GIL, T. Experiências colaborativas no projeto Atlas Digital da América Lusa. Educação em Foco, Juiz de Fora, v. 24, n. 2, p. 593-614, 2019.

GOLD, M. (Ed.). Debates in the digital humanities. Minneapolis: University of Minnesota Press, 2012.

; KLEIN, L. (Ed.). Debates in the digital humanities. Minneapolis: University of Minnesota Press, 2016.

GOMES, K. R. F.; FERLA, L.; MARIANO, R. et al. A platform for collaborative historical research based on volunteered geographical information. Journal of Information and Data Management, v. 9, p. 291-304, 2018. Disponível em: <https://periodicos.ufmg.br/index.php/jidm/article/view/426/9820 >. Acesso em: 16 dez. 2019.

GREGORY, I.; ELL, P. Historical GIS: technologies, methodologies and scholarship. Cambridge: Cambridge University Press, 2007.

HALL, G. There are no digital humanities. In: GOLD, M. K. (Ed.). Debates in the digital humanities. Minneapolis: University of Minnesota Press, 2012.

HUGHES, L. et al. Digital methods in the humanities: understanding and describing their use across the disciplines. In: SCHREIBMAN, S.; SIEMENS, R.; UNSWORTH, J. (Ed.). A new companion to digital humanities. Malden: Blackwell, 2016. 
JORGE, J. O rio que a cidade perdeu: o Tietê e os moradores de São Paulo, 1890-1940. São Paulo: Alameda, 2006.

KLEIN, L.; GOLD, M. Digital humanities: the expanded field. In: GOLD, M. (Ed.). Debates in the digital humanities. Minneapolis: University of Minnesota Press, 2012.

KOGAN, G. The socio-environmental history of the floods in São Paulo, 1887-1930. Tese (Master of Science), Unesco IHE, 2013.

MARQUES, J. B. Trabalhando com a história romana na Wikipédia: uma experiência em conhecimento colaborativo na universidade. Revista História Hoje, v. 2, n. 3, 2013.

; LOUVEM, O. S. A Wikipédia como diálogo entre universidade e sociedade: uma experiência em extensão universitária. In: XIX WORKSHOP DE INFORMÁTICA NA ESCOLA (WIE 2013), 2013. Anais... Disponível em: <https://dx.doi.org/10.5753/CBIE.WIE.2013.70 >. Acesso em: 16 dez. 2019.

MCCARTHY, W. Becoming interdisciplinary. In: SCHREIBMAN, S.; SIEMENS, R.; UNSWORTH, J. (Ed.). A new companion to digital humanities. Malden: Blackwell, 2016.

MORAES, R. et al. A wiki-pedagogia no jornalismo: o caso do Projeto Wikipédia da Faculdade Cásper Líbero. Revista Brasileira de Ensino de Jornalismo, v. 6, n. 18, 2016.

O'DONNELL, D. P. et al. Only connect: the globalization of the digital humanities. In: SCHREIBMAN, S.; SIEMENS, R.; UNSWORTH, J. (Ed.). A new companion to digital humanities. Malden: Blackwell, 2016.

PACKER, A. L. et al. Aos 20 anos, a rede SciELO atualiza prioridades e avança para a ciência aberta [online]. SciELO em Perspectiva, 2018. Disponível em: <https://blog.scielo.org/blog/2018/09/17/aos-20-anos-a-redescielo-atualiza-prioridades-e-avanca-para-a-ciencia-aberta>. Acesso em: 16 dez. 2019.

PARRA, H. et al. Infraestruturas, economia e política informacional: o caso do Google Suite for Education. Mediações: Revista de Ciências Sociais, v. 23, p. 63-99, 2018.

PRESCOTT, A. Beyond the digital humanities center. In: SCHREIBMAN, S.; SIEMENS, R.; UNSWORTH, J. (Ed.). A new companion to digital humanities. Malden: Blackwell, 2016.

RAMSAY, S.; ROCKWELL, G. Developing things: notes toward an epistemology of building in the digital humanities. In: GOLD, M. (Ed.). Debates in the digital humanities. Minneapolis: University of Minnesota Press, 2012.

ROBERTSON, S. The differences between digital humanities and digital history. In: GOLD, M.; KLEIN, L. (Ed.). Debates in the digital humanities. Minneapolis: University of Minnesota Press, 2016.

RODRIGUES, A. 0 ensino de história na era digital: potencialidades e desafios. In: DURÃO, S.; FRANÇA, I. (Org.). Pensar com método. Rio de Janeiro: Papéis Selvagens, 2018. p. 145-175.

ROSENZWEIG, R. Can history be open source? Wikipedia and the future of the past. The Journal of American History, v. 93, n. 1, 2006.

SANTOS, F. A. Domando águas: salubridade e ocupação do espaço na cidade de São Paulo, 1875-1930. São Paulo: Alameda/Fapesp, 2011.

; JORGE, J.; FERLA, L.; ATIQUE, F. et al. A enchente de 1929 na cidade de São Paulo: memória, história e novas abordagens de pesquisa. Revista do Arquivo Geral da Cidade do Rio de Janeiro, v. 8, 2014. 
SCHREIBMAN, S.; SIEMENS, R.; UNSWORTH, J. (Ed.). A companion to digital humanities. Malden: Blackwell, 2004.

i___ (Ed.). A new companion to digital humanities. Malden: Blackwell, 2016.

SVENSON, P. Beyond the big tent. In: GOLD, M. (Ed.). Debates in the digital humanities. Minneapolis: University of Minnesota Press, 2012.

. Sorting out the digital humanities. In: SCHREIBMAN, S.; SIEMENS, R.; UNSWORTH, J. (Ed.). A new companion to digital humanities. Malden: Blackwell, 2016.

THOMAS III, W. G. The promise and the contested nature. In: SCHREIBMAN, S.; SIEMENS, R.; UNSWORTH, J. (Ed.). A new companion to digital humanities. Malden: Blackwell, 2016.

WARWICK, C. Building theories or theories of building?. In: SCHREIBMAN, S.; SIEMENS, R.; UNSWORTH, J. (Ed.). A new companion to digital humanities. Malden: Blackwell, 2016. 